\title{
Effect of Dietary Omega-3 Fatty Acids on Retinal Function of Very-Low-Birth-Weight Neonates ${ }^{1}$
}

\author{
RICARDO D. UAUY, DAVID G. BIRCH, EILEEN E. BIRCH, JON E. TYSON, AND \\ DENNIS R. HOFFMAN \\ Department of Pediatrics [R.D.U., J.E.T., D.R.H.] and Ophthalmology [D.G.B., E.E.B.] and Human Nutrition \\ Center [R.D.U., D.R.H.] University of Texas Southwestern Medical Center, Dallas, Texas 75235-9063 and The \\ Retina Foundation of the Southwest, Dallas, Texas 75231 [D.G.B., E.E.B.]
}

\begin{abstract}
Retinal function was assessed by electroretinogram in 32 neonates randomly assigned to formulas of different $\omega-3$ fatty acid content and in 10 infants fed human milk. All neonates had a birth weight of 1000-1500 $\mathrm{g}$ and were fed study diets from d $\mathbf{1 0}$ to $\mathbf{4 5}$ or discharge. Group $A$ received formula containing predominantly 18:2 $\omega-6$. Group B received a balanced mix of 18:2 $\omega-6$ and 18:3 $\omega$ 3. Group $C$ was given a formula containing both essential fatty acids and supplemented with marine oil to provide 22:6 $\omega-3$ content similar to that of human milk. The fatty acid composition of plasma and red blood cell (RBC) lipids were similar for all groups on entry but marked dietinduced differences were found after feeding the study diets. Group $\mathrm{C}$ was comparable to the human milk-fed group, but group A had lower 22:6 $\omega-3$ and $\omega-3$ long-chain polyunsaturated fatty acids (LCPUFA) in plasma and RBC membranes. Cone function was not affected by dietary essential fatty acids. Rod electroretinogram thresholds were significantly higher for group A relative to the human milk-fed group and group $\mathrm{C}$ and significantly correlated with RBC $\omega-3$ LCPUFA ( $r=-0.63, p<0.0001) ; 44 \%$ of the variance could be explained by RBC and plasma $\omega-3$ LCPUFA content. Rod electroretinogram amplitude was significantly lower for group A relative to the human milkfed group and group $C$ and related to plasma 22:6 $\omega-3(r$ $=0.55)$ and total $\omega-3$ LCPUFA $(r=0.58)$ (both $\mathrm{p}<$ $0.0001) ; 42 \%$ of the variance was explained by plasma $\omega-$ 3 LCPUFA, the ratio of $\omega-6 / \omega-3$ LCPUFA in RBC, and gestational age at birth. Our results support an essential role for $\omega-3$ fatty acids in retinal development. (Pediatr Res 28: 485-492, 1990)
\end{abstract}

\section{Abbreviations}

18:2 $\omega-6$, linoleic acid

18:3 $\omega-3, \alpha$-linolenic acid

EPA, eicosapentaenoic acid, 20:5 $\omega-3$

DHA, docosahexaenoic acid, 22:6 $\omega-3$

FA, fatty acid

EFA, essential fatty acid

PUFA, polyunsaturated fatty acid

LCPUFA, PUFA with greater than 18 carbon chain length

ERG, electroretinogram

VLBW, very low birth weight

Received March 6, 1990; accepted May 31, 1990.

Correspondence and reprint requests: Ricardo Uauy, M.D., Ph.D., Department of Pediatrics, University of Texas Southwestern Medical Center, 5323 Harry Hines Blvd., Dallas, TX 75235-9063.

Supported in part by National Institute of Child Health and Development Gran HD 22380 (RU), United Cerebral Palsy Research Foundation UCP R 375-87 (RU), and National Eye Institute Grants EY 05235 (DB), EY 05236 (EB), and GCRCC Pediatric Subunit USPHS M01-RR0063.

'Presented in part at FASEB 1989 Meeting, New Orleans, LA.
PTHM, preterm human milk

$\mathrm{RBC}$, red blood cell

CFF, critical fusion frequency

ANOVA, analysis of variance

EFA deficiency has been well characterized in experimental animals, in children fed skimmed milk, and in children and adults receiving fat-free parenteral nutrition (1-3). Metabolism of EFA, 18:2 $\omega-6,18: 3 \omega-3$, and the monounsaturated FA, oleic acid, is illustrated in Figure 1 and has been reviewed recently by us $(4)$ and others $(5,6)$. The desaturation steps necessary for the synthesis of DHA from 18:3 $\omega-3$ are slow and inefficient, suggesting that this important coumpound may be required per se (4, 7-9).

Fetal intrauterine accretion of EFA for the human have been studied during the past decade. Direct analysis of 15 human neonates from $22 \mathrm{wk}$ gestational age to term indicated that approximately $400 \mathrm{mg}$ of $\omega-6$ and $50 \mathrm{mg}$ of $\omega-3$ EFA per $\mathrm{kg}$ of body weight were deposited daily during late gestation. On a relative basis, brain and retinal phospholipids had the highest content of LCPUFA (10). Levels of 18:2 $\omega-6$ and 18:3 $\omega-3$ remained stable in brain lipids during late gestation, whereas the LCPUFA (20:4 $\omega-6$ and 22:6 $\omega-3)$ exhibited the greatest rise. Accretion of these FA also continued postnatally in human brain tissue (11). Thus, a preterm infant will be deprived of critical EFA intrauterine accretion and because of insufficient desaturase activity may require preformed LCPUFA in addition to parent EFA supplied by the diet.

Linoleic acid alone may be insufficient to fully satisfy EFA nutrition during late fetal and early postnatal life. A possible need for 18:3 $\omega-3$ and/or $\omega-3$ LCPUFA is suggested by the altered FA pattern, abnormal visual function, and peripheral neuropathy observed on an 18:3 $\omega$-3-free parenteral diet in a human (12). Impaired visual development in newborn rhesus monkeys has been correlated with a linoleate-rich, $\alpha$-linolenate-poor diet and with decreased accretion rates of $\omega-3$ LCPUFA in the developing brain (13-15). Visual acuity, as measured by preferential looking response, was reduced by $50 \%$ after 8 wk of age in $\omega$-3-deprived primates compared with controls (13). The feeding of an artificial formula with a high linoleate content may aggravate the effects of low $\omega-3$ FA intake because linoleate competes with $\alpha$-linolenate for $\Delta^{6}$ desaturation (14). Nonhuman primates fed a similar diet during prenatal and early postnatal life had a low plasma phospholipid DHA content at birth and almost nondetectable levels at 12 wk of age $(13,15)$. A direct correlation between brain and $\mathrm{RBC}$ membrane phospholipid FA compositions also has been demonstrated, suggesting that RBC lipid analysis may be used to evaluate $\omega-3$ status of brain and retina (16).

ERG studies in the rat have shown that the a-wave of the 


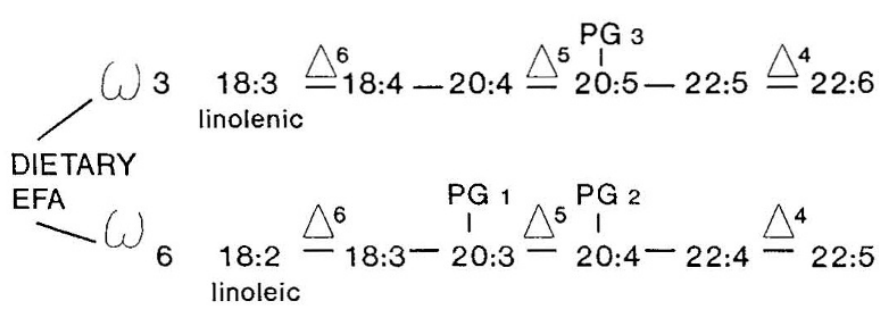

$$
\begin{aligned}
& \text { ENDOGENOUS FA } \\
& \begin{array}{c}
\text { 16:0-18:0 }-18: 1-18: 2-20: 2-20: 3-22: 3 \quad \triangle_{9} \\
\text { oleic }
\end{array}
\end{aligned}
$$

Fig. 1. Metabolic pathways for elongation and desaturation for both $\omega-3$ (18:3, $\alpha$-linolenic acid) and $\omega-6$ series (18:2, linoleic acid) dietary parent EFA. Elongation occurs in two carbon units and $\Delta$-desaturases $(\Delta 6, \Delta 5, \Delta 4)$ introduce double bonds at carbons 6,5 , and 4 from carboxy terminus. FA 20:3 $\omega-6,20: 4 \omega-6$ (arachidonic acid), and EPA are precursors of prostaglandins $(P G)$ of 1,2 , and 3 series, respectively. DHA is of critical significance in retinal and brain development. The product of endogenous FA metabolism is 16:0; it can be elongated to $18: 0$ and desaturated to $18: 1 \omega-9$ (oleic acid), which may also be derived from the $\operatorname{diet}(4)$.

ERG, primarily related to photoreceptor function, is significantly reduced by EFA deficiency (17). The experimental group fed an 18:2 $\omega$-6-enriched diet had partial improvement relative to the group fed an EFA-deficient diet but was still $33 \%$ lower than the $\omega$-3 FA-supplemented group (17). Another relevant animal study showed superior learning capacity of rats fed soybean oil $(18: 2$ $\omega-6 / 18: 3 \omega-3=6)$ compared with those fed safflower oil $(18: 2 \omega-$ $6 / 18: 3 \omega-3=258)(18)$. The former had higher levels of DHA in brain lipids, supporting the essential role of $\omega-3 \mathrm{FA}$ in this tissue. Although the animal data are suggestive, no conclusive study supports the need for $\omega-3$ FA in the human diet.

The VLBW infant has nearly absent peripheral adipose tissue and decreased reserves of EFA. Studies of VLBW infants given fat-free glucose-amino acid mixtures show evidence of EFA deficit in plasma phospholipids by postnatal d 5 (19). The problem of $\omega-3$ EFA deficit in infancy has not been fully addressed. However, considering that the elongation-desaturation pathways are most likely limited in early life, the dietary supply of long-chain $\omega$-3 PUFA will not match the intrauterine accretion rates unless the VLBW infant receives human milk (9-11). Given the composition of preterm breast milk, an intake of $200 \mathrm{~mL} / \mathrm{kg}$ provides the $1300 \mathrm{~g}$ neonate with $139 \mathrm{mg}$ of total $\omega-3 \mathrm{EFA}$ including $70 \mathrm{mg} \omega-3$ LCPUFA per day (20). This provision of EFA and LCPUFA meets the daily needs based on the accretion rates during development. Corn oil-based formula as compared with human milk is lower in oleic acid, higher in 18:2 $\omega-6$, and has very little $\omega-3$ FA. Soy oil-based formula provides ample 18:3 $\omega-3$ but contains no $\omega-3$ LCPUFA $(4,21)$.

The goal of our study was to evaluate whether $\omega-3 \mathrm{FA}$ are essential for the developing retina in humans by measuring the effect of dietary EFA on rod and cone function in VLBW neonates early in postnatal life. The diets used served to test if the $18: 3 \omega-3$, provided by replacing corn with soy oil in mediumchain triglyceride/coconut/corn oil-based formula, was necessary for optimal retinal development or if $\omega-3$ LCPUFA (EPA and DHA) from marine sources were also required. The human milkfed group was considered normative because the $\omega-3$ FA supply was adequate to meet accretion needs.

\section{MATERIALS AND METHODS}

Subjects. Newborns were eligible for the study if they had a birth weight of $1000-1500 \mathrm{~g}$ that was appropriate for gestational age, if they were able to receive enteral feedings (70-120 kcal/ $\mathrm{kg}$ ), and if they were free of major neonatal morbidity by $\mathrm{d} 10$. Ten infants fed PTHM (their own mother's milk) from birth served as controls. Formula groups were matched by birth weight (1000-1249 and 1250-1500 g) and sex. They were randomly assigned by d 10 of life to one of three test diets that were continued throughout the study until visual testing was completed at 36 wk postconception. Initial feedings before d 10 consisted of diluted standard premature formula or a small volume of breast milk for the human milk group supplemented by parenteral glucose and amino acids. Intravenous lipids were allowed up to $\mathrm{d} 7$ of life. Infants were excluded for the following types of significant neonatal morbidity likely to influence feeding or visual responses: respirator treatment for more than $7 \mathrm{~d}$, congenital infection, any major malformation, bowel resection, and grade III or IV intracranial hemorrhage. Infants were also excluded for maternal factors such as abnormal dietary patterns, strict vegetarian or vegan diets, or metabolic disease that may affect EFA status of mother or fetus. All infants were checked at $30-40 \mathrm{~d}$ by an ophthalmologist for degree of retinopathy of prematurity. Those with retinopathy grade 3 or greater (likely to produce lasting visual impairment) were not included in the visual response evaluation (22). Care was taken to avoid sampling blood within $48 \mathrm{~h}$ of blood transfusion. This time was considered sufficient for a new equilibrium of plasma lipid FA composition. The project was approved by the Institutional Review Board; parents were informed on the nature of the study and written consent was obtained in all cases. All infants received vitamin and mineral supplements in accordance with the nursery routine to meet present recommendations for VLBW infants including taurine supplementation. Practices in our unit include providing daily multivitamins drops (A, C, and D) and vitamin E, 25 IU per day for $14 \mathrm{~d}$ after feedings are well tolerated. Iron-supplemented formula is given after $30 \mathrm{~d}$ of age.

VLBW neonates enrolled in this study from July 1987 to June 1989 were monitored daily by a research nurse. Volume of intake, feeding tolerance, and weight were recorded daily. Length and head circumference were measured weekly. Clinical care was provided by the attending neonatologist and resident physicians who were familiar with the study but blinded to diet group assignment.

Diets. The human milk group received refrigerated or prefrozen (gently thawed) PTHM supplemented with a standardized human milk fortifier (Enfamil, Mead-Johnson Bristol-Myers Company, Evansville, IN) to assure comparable macro- and micronutrient intake. Pooled composite samples of PTHM obtained before feeding were stored at $-70^{\circ} \mathrm{C}$ and analyzed for total fat and FA composition on d 10,20, and 30. The human milkfed group received a mean of $75 \%$ of their intake as PTHM (range, $60-100 \%$ ); formula C, containing LCPUFA of the $\omega-3$ series, was used as a supplement if mothers were unable to fully provide for their infants' need. Groups A, B, and C were fed formulas adapted to the needs of VLBW neonates with a protein content of $2.4 \mathrm{~g} / \mathrm{dL}$, whey:casein $60 / 40$, carbohydrates $8.9 \mathrm{~g} / \mathrm{dL}$, lactose:glucose polymers $40 / 60$, fat $4.1 \mathrm{~g} / \mathrm{dL}$ with varying amounts of EFA. Full details of the FA composition of these formulas as compared with PTHM are given in Table 1. Formula A, low in all $\omega-3 \mathrm{FA}$, corresponds to the fat composition of Enfamil Premature (Mead-Johnson Bristol-Myers Co.) before 1987. Formula B contains ample $18: 3 \omega-3$ but no $\omega-3$ LCPUFA. Formula C, supplemented with $18: 3 \omega-3$ and marine oils, is high in EPA and DHA. These formulations were specially prepared for this study by Mead Johnson Nutritional Division (Evansville, IN). All infants consumed study diets for at least $20 \mathrm{~d}$ and up to $35 \mathrm{~d}$ before blood sampling as determined by discharge criteria (weight $>1800 \mathrm{~g}$ ).

The vitamin and mineral content of the milk formula met the recommendations of the American Academy of Pediatrics for low-birth-weight neonates. Vitamin E content was adjusted to secure at least $2 \mathrm{mg}$ of tocopherol per $\mathrm{g}$ of unsaturated FA in the formula. This has been shown to prevent FA peroxidation in the product for at least 24 mo.

$E R G$. Full-field ERG were obtained at 36 wk postconception 
Table 1. FA composition of study diets based on gas chromatographic analysis (mean values $\mathrm{g} / 100 \mathrm{~g}$ of lipid)

\begin{tabular}{lrrrr}
\hline & & \multicolumn{3}{c}{ Fuman } \\
\cline { 3 - 5 } & milk* & A & \multicolumn{1}{c}{ B } & C \\
\hline $6: 0$ & & 2.4 & 2.5 & 2.5 \\
$8: 0$ & 1.4 & 28.3 & 28.3 & 28.4 \\
$10: 0$ & 3.2 & 10.4 & 10.4 & 10.4 \\
$12: 0$ & 4.7 & 10.5 & 10.5 & 10.8 \\
$14: 0$ & 8.0 & 3.4 & 3.4 & 4.0 \\
$16: 0$ & 19.2 & 6.1 & 5.8 & 6.4 \\
$18: 0$ & 8.9 & 1.3 & 2.1 & 1.7 \\
$18: 1 \omega-9$ & 35.5 & 11.8 & 10.3 & 10.7 \\
$18: 2 \omega-6$ & 12.7 & 24.2 & 20.8 & 20.4 \\
$18: 3 \omega-3$ & 0.8 & 0.5 & 2.7 & 1.4 \\
$\omega-6>C 18$ & 1.5 & 0 & 0 & 0.1 \\
$\omega-3>C 18$ & 0.5 & 0 & 0 & $1.0 \ddagger$ \\
Total $\omega-6 / \omega-3$ & 11.4 & 48.4 & 7.7 & 8.5 \\
\hline
\end{tabular}

* Representative $\mathrm{d} 20$ breast-milk sample.

† Formula $\mathrm{A}$ was based on medium-chain triglyceride/coconut/corn oil blend, formula $\mathrm{B}$ on medium-chain triglyceride/coconut/soy blend, and formula $\mathrm{C}$ on medium-chain triglyceride/coconut/soy/marine oil blend.

$\ddagger$ EPA content was $0.65 \%$ and DHA content was $0.35 \%$, total $\omega-3>$ C18 was $1.0 \%$

from each infant. All recordings and analyses were conducted without prior knowledge of diet group assignment. The pupil was dilated using a mixture of cyclopentolate hydrochloride $(0.2 \%)$ and phenylephrine hydrochloride (1\%). During the darkadaptation period ( $30 \mathrm{~min})$, the infant was fed and typically fell asleep. The infant was swaddled and placed in an isolette. A head roll was used to stabilize neck and head posture. At the end of the dark-adaptation period, two drops of proparacaine hydrochloride $(0.5 \%)$ were instilled under dim red illumination to topically anesthetize the cornea. Pupil size for each infant was measured with a millimeter scale. A ground electrode was placed on the forehead and a premature infant Burian-Allen bipolar contact lens electrode filled with methylcellulose was placed on the eye. Stimuli were delivered within a spherical diffusing dome lowered over the isolette. The dome contained a small aperture for viewing the infant under dim red illumination during the session. Responses were obtained only when the pupil was clearly visible within the contact lens electrode. A minimum of 20 responses for each stimulus condition were amplified (gain = $10000 ;-3$ decibel cutoff at 2 and $300 \mathrm{~Hz}$ ) and recorded on FM tape for subsequent computer analysis.

Responses were obtained in ascending order to an intensity series of short-wavelength $\left(\lambda_{\max }=450 \mathrm{~nm}\right.$, half-bandwidth $=55$ $\mathrm{nm}$ ) stimuli that selectively stimulate the rod system. Subsequently, a series of responses was obtained to long-wavelength $\left(\lambda_{50 \% \text { cut-on }}=605 \mathrm{~nm}\right)$ stimuli that predominantly stimulate the cone system. Responses to long-wavelength stimuli were computer-subtracted from responses to photopically-matched shortwavelength stimuli to isolate rod responses at retinal illuminances above $1.0 \log$ scotopic troland-s, which otherwise produce mixed rod and cone responses $(23,24)$. Responses to white flickering stimuli $(20-60 \mathrm{~Hz})$ in the dark were amplified (gain $=200000)$ selectively at the stimulus frequency and subsequently computer averaged $(n=50)$. The best-fit Naka-Rushton function (25) was used to determine the relationship between rod peak-to-peak amplitude and retinal illuminance. A nonlinear analysis was used to determine the parameters of the Naka-Rushton function:

$$
\frac{\mathrm{V}}{\mathrm{V}_{\max }}=\frac{\mathrm{I}}{\mathrm{I}+\mathrm{k}}
$$

where $\mathrm{V}=$ rod peak-to-peak amplitude, $\mathrm{V}_{\max }=$ maximum rod peak-to-peak amplitude, $I=$ retinal illuminance in scotopic troland-s, and $\mathrm{k}=$ retinal illuminance at half maximum ampli- tude. Rod threshold $(2.0-\mu \mathrm{V}$ criterion) was derived from the Naka-Ruston parameters:

$$
\text { Log threshold }=\log \mathrm{k}+0.3-\log \left(\mathrm{V}_{\max }-2\right)
$$

Linear regression (peak-to-peak amplitude versus log photopic retinal illuminance) was used to derive dark-adapted cone threshold (2.0- $\mu \mathrm{V}$ criterion) for long-wavelength stimuli. CFF $(0.3-\mu \mathrm{V}$ criterion), was determined from the high-frequency limb of the function relating log amplitude to log temporal frequency.

FA composition. To evaluate the effect of the different dietary supplies of EFA on plasma and membrane lipids, we measured the FA composition of total plasma lipid and total RBC membrane lipid. These indicators can be used to assess EFA status and identify signs of excess or deficits in the diet. RBC membrane phospholipds are correlated with changes in FA composition of other membranes including brain $(15,16)$. Blood samples were obtained by venipuncture from a small arm vein before randomization at $10 \mathrm{~d}$ of age and repeated at discharge (30-45 d of age). Plasma was separated from the sample by centrifugation. Plasma and packed RBC lipids were extracted using methanol:chloroform as described by Bligh and Dyer (26). Lipid samples were analyzed immediately or stored in solvent containing butylated hydroxytoluene $(0.005 \%)$ as antioxidant at $-20^{\circ} \mathrm{C}$ for later chromatographic analysis. FA were saponified and methylated simultaneously with $14 \%$ boron trifluoride in methanol (27). FA methyl esters were stored in antioxidant-containing solvent and under nitrogen at $-20^{\circ} \mathrm{C}$ until analysis. Separation and quantification of FA methyl esters was done using flame ionization detector capillary gas chromatography comparing their retention time with authentic standards (28). We used a Hewlett-Packard model no. 5890 gas chromatograph (HewlettPackard Co., Palo Alto, CA) equipped with a 0.25 -mm bore, 30 m capillary column filled with SP-2330 stationary phase. Helium at a flow of $1 \mathrm{~mL} / \mathrm{min}$ was used as a carrier gas and the split ratio was 9:1. Temperature programming for the chromatograph consisted of $150^{\circ} \times 5 \mathrm{~min}, 4^{\circ} / \mathrm{min}$ to $220^{\circ}, 220^{\circ} \times 8 \mathrm{~min}, 15^{\circ} \%$ $\min$ to $240^{\circ}, 240^{\circ} \times 8 \mathrm{~min}$, return to $150^{\circ}$, and equilibrate 1 min. The relative concentration of individual FA were expressed as percent of total FA equal to or greater than six carbons for diets and greater than 14 carbons for plasma and membrane samples.

Integrated data from each gas chromatogram was filed and stored on an IBM AT computer. A customized software package developed to allow for semi-automated identification of FA methyl esters served to ensure accurate peak identification. The coded data were sorted and compiled into Lotus files for inspection and statistical analysis. Formula FA analysis by MeadJohnson confirmed in our laboratory used methodologies based on procedures of the Association of Official Analytical Chemists (29).

Data analysis. Results were analyzed using a one-way ANOVA to evaluate the effect of diet ( $\omega-3$ FA supply). Descriptive statistics were computed for all dependent variables in the analysis. Comparisons among the diet groups were done using an $\alpha$ of 0.05 ; significant main effects were analyzed post-hoc, using NewmanKeuls multiple comparison procedure. Simple and multiple regression were used to relate plasma and RBC membrane lipid composition with indices of rod and cone function. Nonparametric analysis of diet effects were also performed using nonparametric ANOVA and the $\chi^{2}$ test for rod threshold and maximum amplitude.

\section{RESULTS}

A total of 123 mothers delivering babies weighing 1000-1500 $\mathrm{g}$ at birth were approached before discharge from the hospital to obtain approval to enter their babies in the study; 68 approved and signed consent forms. Forty-four of these infants met eligibility criteria by the 10th $\mathrm{d}$ after birth and were effectively enrolled in the study. Results from 42 patients were available at 
the time of this analysis because two of 44 patients were dropped from the study due to medical complications (one for necrotizing enterocolitis and one for patent ductus arteriosus requiring surgery). Information on the 42 infants is presented in Table 2. Comparability of subjects by diet group for the main intervening variables was tested and is summarized. Subjects in the different diet groups had comparable birth weight, length, gestational age, weight at entry to the study, and gross energy intake throughout the study. The weight and postconceptional age at the time of visual testing were also similar. Information on the mean number of days to reach $1800 \mathrm{~g}$ and anthropometry at $40 \mathrm{wk}$ are also provided for the study groups. The human milk group required significantly longer time to reach $1800 \mathrm{~g}$ as compared with each of the three formula groups $(p<0.05)$.

Responses from a dark-adapted infant at $36 \mathrm{wk}$ postconception to an ascending series of long-wavelength flashes are shown in Figure $2 a$. The cone origin of these responses is evident from the relatively short b-wave implicit times (time from stimulus to positive peak). As is the case in adults, cone b-wave implicit time does not vary with retinal illuminance. Amplitudes as a function of retinal illuminance are plotted in Figure $2 b$ along with the best-fit regression line (solid line) and the mean adult function (dotted line). A $2.0-\mu \mathrm{V}$ criterion was used to determine cone threshold from the best-fit regression line for each infant. Although the slopes are clearly different, cone threshold in this infant was within $0.3 \mathrm{log}$ unit of mean adult values.

Cone responses to a series of flicker rates are shown for a representative 36-wk-old infant in Figure $3 a$. Flicker rates less than $20 \mathrm{~Hz}$ were not used because of possible rod intrusion. In general, cone amplitude decreased systematically with increasing flicker rate and was nondetectable by $60 \mathrm{~Hz}$. Peak-to-peak amplitude is plotted in Figure $3 b$ (open circles) along with the mean adult function (dashed curve). CFF for each infant was defined as the frequency producing a $0.3-\mu \mathrm{V}$ amplitude (dotted horizontal line). For this particular infant, $\mathrm{CFF}$ was $55 \mathrm{~Hz}$. Mean $\pm \mathrm{SD}$ cone thresholds and CFF for each dietary group are shown in Table 3. ANOVA showed no significant differences among groups.

Responses from a dark-adapted 36-wk-old infant to a series of short-wavelength flashes are shown in Figure $4 a$. The rod origin of responses to flashes less than $1.19 \mathrm{log}$ scotopic troland-s is evident from the waveform, the prolonged b-wave implicit time, and the decrease in b-wave implicit time with increasing retinal illuminance. For responses of $1.19 \log$ scotopic troland-s and above, the rod component of the response was isolated by computer-subtracting the response to a photometrically-matched long-wavelength stimulus (24). Log amplitude is plotted as a function of $\log$ retinal illuminance in Figure $4 b$ (open circles) along with the best-fit Naka-Rushton function (solid curve). Relative to the mean adult function (dashed curve), infants showed much lower values of $V_{\max }$ (maximum b-wave amplitude) and much higher values of $\log \mathrm{k}$ (measure of sensitivity).
Rod threshold was determined from the Naka-Rushton function as the retinal illuminance necessary to produce a $2.0-\mu \mathrm{V}$ response. Of 42 infants tested, 14 had nondetectable rod ERG or rod responses over too limited a range for the Naka-Rushton analysis (one in the PTHM-fed group, two in group C, four in group B, and seven in group A). These infants were assigned values for $\log \mathrm{k}$ and rod threshold of 1.9 and $1.3 \log$ scotopic troland-s based on the maximum retinal illuminance available. $\log \mathrm{V}_{\max }$ was then calculated from the Naka-Rushton function as $1.0 \log \mu \mathrm{V}$.

Results for parameters of the Naka-Rushton function are shown in Figure 5. ANOVA revealed significant differences among groups in $\log \mathrm{V}_{\max }$ and rod threshold (Table 3 ). Rod bwave thresholds were significantly higher in the $\omega-3$ deficient group (formula A) than in the groups receiving long-chain $\omega-3$ (human milk and formula $C$ ). Rod thresholds were virtually identical in infants receiving EPA + DHA supplemented formula (formula C) and human milk-fed infants. Similarly, maximum amplitudes $\left(\log \mathrm{V}_{\max }\right.$ ) were lowest in infants given formula $\mathrm{A}$, which provided predominantly $\omega-6 \mathrm{FA}$, and highest in infants fed human milk or long-chain $\omega$-3-enriched formula. Post-hoc comparisons of $\mathrm{V}_{\max }$ for group $\mathrm{B}$ receiving solely $18: 3 \omega-3$ versus the human milk-fed group gave a $p$ value of $<0.05$, and for group $\mathrm{B}$ versus $\mathrm{C}$ gave a $p$ value of $<0.06$. Analysis of the data by nonparametric ANOVA and $\chi^{2}$ test gave a $p$ value of $<0.02$ for rod threshold and maximum amplitude in the comparison of diet groups. Differences among groups in $\log \mathrm{k}$ did not reach statistical significance.

The FA composition of plasma lipids on admission to the study (d 10) was similar in the four study groups (data not shown) except for a significant difference in oleic acid (18:1 $\omega-9)$ content in the group receiving human milk: $27 \mathrm{~g} / 100 \mathrm{~g}$ of lipid versus 20 $\mathrm{g} / 100 \mathrm{~g}$ in the three formula groups (ANOVA $F=7.4, p<$ $0.001)$. FA composition of RBC lipids was similar in all four groups on $\mathrm{d} 10$ (data not shown).

The results for plasma lipids after 20-35 d of consuming study diets are shown in Table 4. Significant diet effects were demonstrable using ANOVA. The human milk-fed infants had a higher monounsaturated FA and lower 18:2 $\omega-6$ content relative to all formula-fed groups. Group C, receiving long-chain $\omega-3$ PUFA, was similar to the human milk-fed group except for higher content of EPA, 22:5 $\omega$-3, and DHA. The $\omega$-3 FA-deficient group A had significantly lower $\omega$-3 derivatives including a substantially lower DHA level. This group also had the highest PUFA $\omega-6 /$ PUFA $\omega-3$, LCPUFA $\omega-6 / \omega-3$, and a significantly lower $22: 6 \omega-$ $3 / 22: 5 \omega-6$ ratio. All are suggestive of $\omega-3$ LCPUFA insufficiency. In addition, a significantly lower sum of $\omega-3$ LCPUFA was observed for group A. Group B had DHA values that were intermediate between the deficient group and the groups receiving long-chain $\omega-3$ FA. Group B had the highest $18: 3 \omega-3$ content (ANOVA $p<0.0001$ ), yet the DHA content (the end product of its elongation and desaturation) was lower than in group $\mathrm{C}$. The

Table 2. Comparability of study groups (mean $\pm S D)$

\begin{tabular}{|c|c|c|c|c|c|}
\hline \multirow[b]{2}{*}{ Variable } & \multicolumn{4}{|c|}{ Study group } & \multirow[b]{2}{*}{$p$} \\
\hline & $\begin{array}{l}\text { Human milk } \\
\quad(n=10)\end{array}$ & $\begin{array}{c}\text { Formula A } \\
(n=10)\end{array}$ & $\begin{array}{c}\text { Formula B } \\
(n=10)\end{array}$ & $\begin{array}{c}\text { Formula C } \\
(n=12)\end{array}$ & \\
\hline Birth wt $(\mathrm{g})$ & $1308 \pm 117$ & $1340 \pm 106$ & $1224 \pm 92$ & $1281 \pm 101$ & NS \\
\hline Birth length $(\mathrm{cm})$ & $39.2 \pm 1.9$ & $39.0 \pm 1.7$ & $38.4 \pm 1.5$ & $39.0 \pm 1.7$ & NS \\
\hline Gestational age (wk) & $30.4 \pm 1.1$ & $30.9 \pm 1.6$ & $29.6 \pm 1.6$ & $30.7 \pm 1.2$ & NS \\
\hline Entry wt $(\mathrm{g})$ & $1211 \pm 86$ & $1295 \pm 144$ & $1173 \pm 130$ & $1241 \pm 118$ & NS \\
\hline Age at visual testing (wk) & $36.1 \pm 1.7$ & $35.2 \pm 0.9$ & $35.1 \pm 1.0$ & $35.3 \pm 0.9$ & NS \\
\hline Wt at visual testing $(\mathrm{g})$ & $1944 \pm 265$ & $1918 \pm 147$ & $2036 \pm 200$ & $1998 \pm 120$ & NS \\
\hline Days to $1800 \mathrm{~g}(\mathrm{~d})$ & $35.1 \pm 4.2^{*}$ & $28.2 \pm 4.7$ & $33.7 \pm 6.2$ & $30.0 \pm 5.9$ & $<0.05$ \\
\hline Wt at $40 \mathrm{wk}(\mathrm{g})$ & $2998 \pm 463$ & $3238 \pm 463$ & $3160 \pm 325$ & $3055 \pm 506$ & NS \\
\hline Length at $40 \mathrm{wk}(\mathrm{cm})$ & $48.0 \pm 2.8$ & $49.6 \pm 1.2$ & $48.6 \pm 2$ & $48.0 \pm 2.2$ & NS \\
\hline Head circumference at $40 \mathrm{wk}(\mathrm{cm})$ & $35.0 \pm 1.8$ & $34.9 \pm 0.5$ & $35.4 \pm 0.8$ & $34.7 \pm 1.0$ & NS \\
\hline
\end{tabular}

\footnotetext{
* Human milk significantly different from the three formula groups using ANOVA.
} 
a
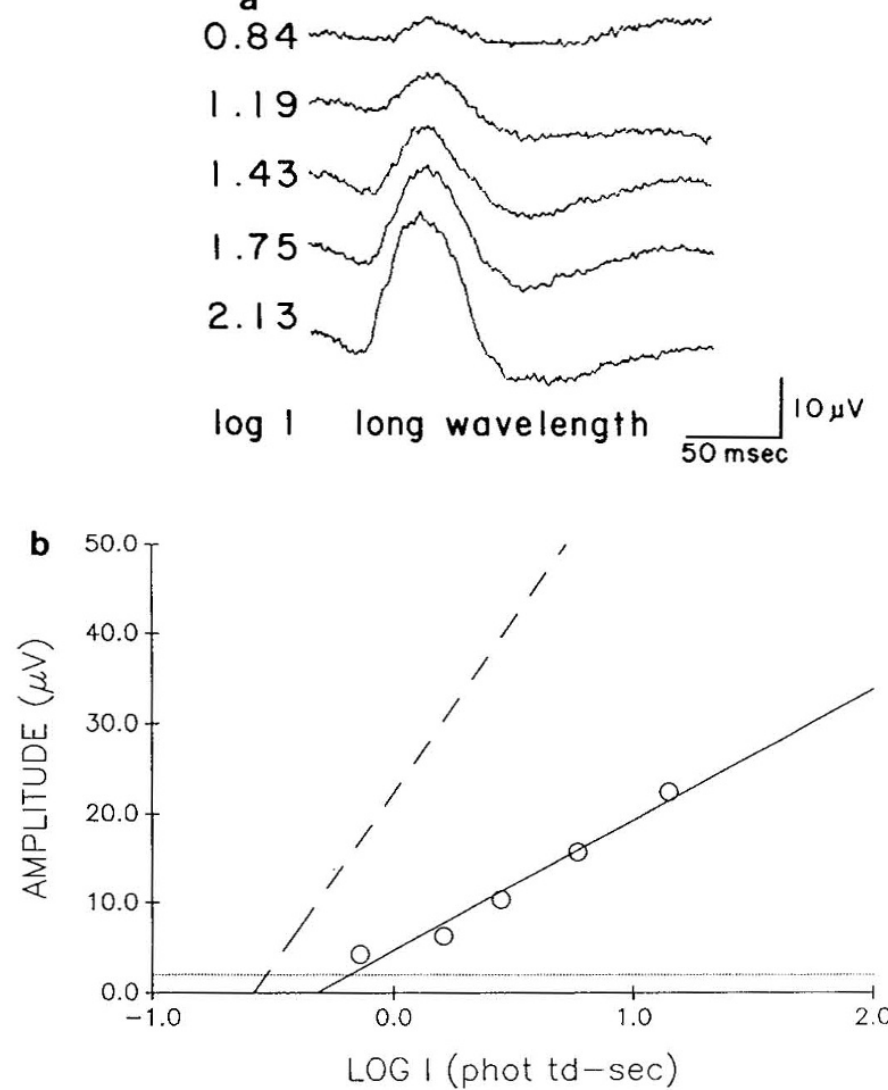

Fig. 2. $a$, Full-field ERG to long-wavelength stimuli from an infant at $36 \mathrm{wk}$ conceptual age. B-wave implicit time does not vary with retinal illuminance $(\log I)$, consistent with a cone origin for the responses. Values to left of each response are retinal illuminance in log photopic troland-s. $b$, Cone peak-to-peak amplitude as a function of retinal illuminance for the infant shown in $a$. Responses near threshold were linearly related to $\log$ retinal illuminance $(\log I)$; these responses were used to derive cone threshold $(2-\mu \mathrm{V}$ criterion, solid line). The dashed line is the mean adult function based on 15 subjects (24).
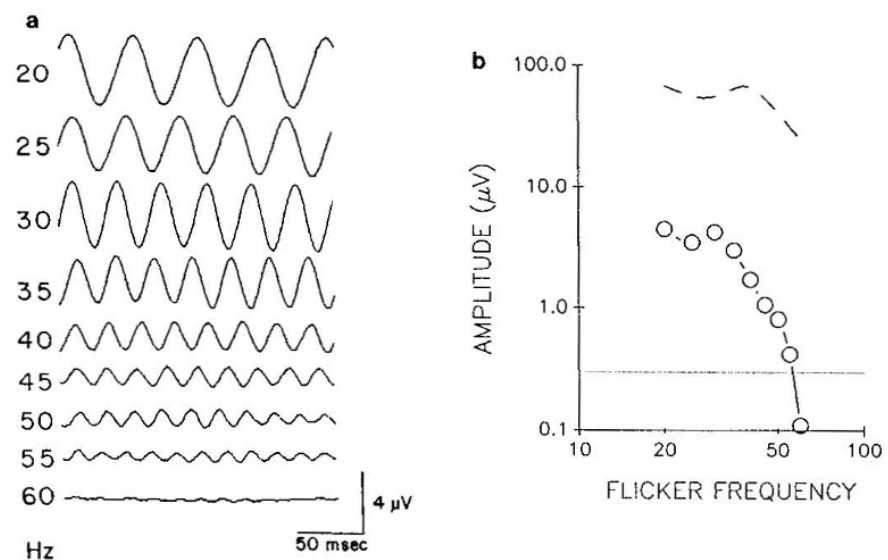

Fig. 3. a, Full-field ERG to flickering stimuli in an infant at $36 \mathrm{wk}$ conceptual age. Numbers to left of each trace refer to flicker rate in cycles/s (Hz). $b$, Cone amplitude as a function of flicker rate for the same infant shown in $a$. The horizontal dotted line is the criterion amplitude $(0.3 \mu \mathrm{V})$ used to derive CFF. The dashed curve is the mean adult function.

interpretation of the product:precursor $\omega-3$ conversion for plasma is confounded by the direct provision of product in the PTHM group and group $C$ and the excess precursor provided in group B.

The results for $\mathrm{RBC}$ membrane lipid analysis presented in Table 5 parallel the diet-induced changes observed for plasma.
The effects are less prominent as evidenced by lower $F$ values. Significant effects observed for group A, fed the deficient formula, include a lower content of $\omega-3$ derivatives, higher $\omega-6 / \omega-3$ PUFA and LCPUFA ratios, and a lower 22:6 $\omega-3 / 22: 5 \omega-6$ ratio compared with the other groups. The overall results for group $\mathrm{C}$ were similar to those for the human milk group. Group A clearly differed from the human milk and formula $C$ groups in $\omega-3$ LCPUFA content. Group B had intermediate values that were not statistically different from those of group $\mathrm{C}$ or the human milk-fed infants.

The relationships between FA composition of plasma and $\mathrm{RBC}$ lipids and the electroretinographic changes were explored by simple and multiple linear regression analysis. Other confounding variables controlled by the defined entry criteria or by randomization were also included in the multiple regression models tested. Significant simple correlations were demonstrated for log rod threshold and RBC 20:5 $\omega-3$ FA content $(r=-0.51$, $p<0.001), 22: 5 \omega-3$ content $(r=-0.52, p<0.001), \omega-3$ LCPUFA content $(r=-0.63, p<0.0001)$, and long-chain $\omega-6 / \omega-3$ ratios $(r=0.45, p<0.006)$. The highest correlation with plasma lipid FA content was seen for the sum of long-chain $\omega$-3 FA $(r=0.36$, $p<0.02$ ). The multiple regression model that best explained the variance in $\log$ rod threshold included $\mathrm{RBC}$ and plasma longchain $\omega-3$ contents ( $p<0.0001$ and $p<0.03$, respectively); the resulting $R$ square was $0.44(F=8.9, p<0.0002)$.

The correlation analysis for $\log \mathrm{V}_{\max }$ revealed that it was related positively to plasma $22: 6 \omega-3(r=0.55, p<0.0001)$ and plasma long-chain $\omega-3$ FA content $(r=0.58, p<0.0001)$ and negatively to the RBC long-chain $\omega-6 / \omega-3$ PUFA ratio $(r=-0.40, p<$ 0.01 ). The multiple regression model that explained the highest percent of variance in $\log \mathrm{V}_{\max }$ included plasma long-chain $\omega-3$ content, RBC long-chain $\omega-6 / \omega-3$ PUFA ratio, and gestational age at birth; the combined $R$ square was $0.42(F=7.8, p<$ $0.0004)$. Birth weight, gestational age at birth, test weight, and test age within the narrow time frame chosen for study were not correlated individually to the measures of rod function evaluated in this study. Cone function was not related to diet nor to the FA composition of plasma or RBC lipids.

\section{DISCUSSION}

This controlled double-blind study provides clear evidence that $\omega-3$ FA are essential for optimal function of the developing retina. Low-birth-weight human neonates are potentially vulnerable to $\omega$-3 FA deficiency because formulas based on corn oil as an EFA supply have low $18: 3 \omega-3$ and, at present, no commercial formula in the United States contains long-chain $\omega-3$ derivatives. Dietary requirements in low-birth-weight infants are relatively high because of the fast accretion rates and absence of EFA reserves.

Present nutritional recommendations for VLBW infants do not include $\omega-3$ as EFA and merely indicate that $18: 2 \omega-6$ is the EFA for the human neonate (30). The essentiality of $\omega-3 \mathrm{FA}$ in the human can now be substantiated by: 1 ) the altered retinal function in low-birth-weight neonates fed an $\omega$-3-deficient diet as reported presently; 2) the occurrence of altered FA composition of blood lipids in infants fed formula low in $\omega-3$ FA (31, 32 ); and 3) the reported nonspecific visual changes and peripheral neuropathy in a handful of chronically ill patients receiving enteral or parenteral nutrition with low or absent $\omega-3$ FA supply (33-35).

Abnormalities of retinal and brain function have been demonstrated in animals fed $\omega$-3-deficient diets throughout the life cycle $(13,15,17,18)$. The opportunity to evaluate this issue in the human was afforded by the fact that standard low-birthweight infant formulas at the time of this study were based on vegetable oils, usually medium-chain triglyceride/coconut/corn oil blends that have low 18-3 $\omega-3$ and relatively high 18:2 $\omega-6$. The observation from the rhesus monkey studies and other in vitro studies of microsomal EFA metabolism suggests that a high 
Table 3. Electroretinographic responses at 36 wk postconceptual age (mean $\pm S D)^{*}$

\begin{tabular}{|c|c|c|c|c|c|c|}
\hline & \multirow{2}{*}{$\begin{array}{l}\text { Human milk } \\
\qquad(n=10)\end{array}$} & \multirow{2}{*}{$\begin{array}{c}\text { Formula A } \\
(n=10)\end{array}$} & \multirow{2}{*}{$\begin{array}{c}\text { Formula B } \\
(n=10)\end{array}$} & \multirow{2}{*}{$\begin{array}{c}\text { Formula } C \\
(n=12)\end{array}$} & \multicolumn{2}{|c|}{ ANOVA } \\
\hline & & & & & $F$ & $p$ \\
\hline \multicolumn{7}{|l|}{ Rod function } \\
\hline log threshold (scot td-s) & $0.414 \pm 0.59^{a}$ & $1.105 \pm 0.37^{h}$ & $0.739 \pm 0.64^{a . b}$ & $0.410 \pm 0.63^{a}$ & 3.390 & $<0.028$ \\
\hline $\log \mathrm{V}_{\max }(\mu \mathrm{V})$ & $1.20 \pm 0.14^{a}$ & $1.02 \pm 0.05^{b}$ & $1.07 \pm 0.13^{a . b}$ & $1.20 \pm 0.17^{a}$ & 4.99 & $<0.005$ \\
\hline $\log k(\operatorname{scot} t d-s)$ & $1.25 \pm 0.54$ & $1.72 \pm 0.31$ & $1.43 \pm 0.6$ & $1.25 \pm 0.55$ & 1.94 & $<0.14$ \\
\hline \multicolumn{7}{|l|}{ Cone function } \\
\hline log threshold (phot td-s) & $-0.11 \pm 0.24$ & $0.09 \pm 0.15$ & $0.04 \pm 0.03$ & $-0.04 \pm 0.24$ & NS & NS \\
\hline $\mathrm{CFF}(\mathrm{Hz})$ & $51.5 \pm 6.6$ & $48.5 \pm 5.6$ & $48.9 \pm 6.3$ & $47.4 \pm 6.9$ & NS & NS \\
\hline
\end{tabular}

* Groups with different superscripts are significantly different $(p<0.05)$ using Newman-Keuls multiple comparison test. Scot td-s, scotopic troland-seconds; phot td-s, photopic troland-seconds.

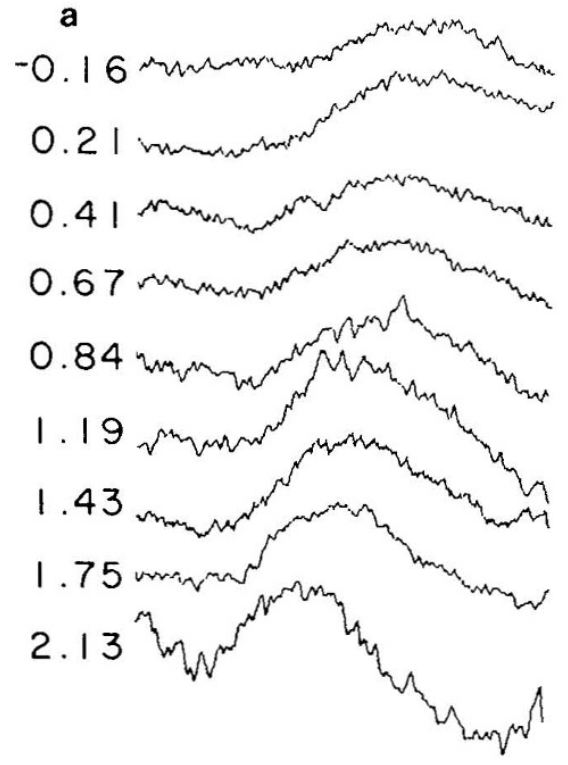

$\log 1$ short wavelength
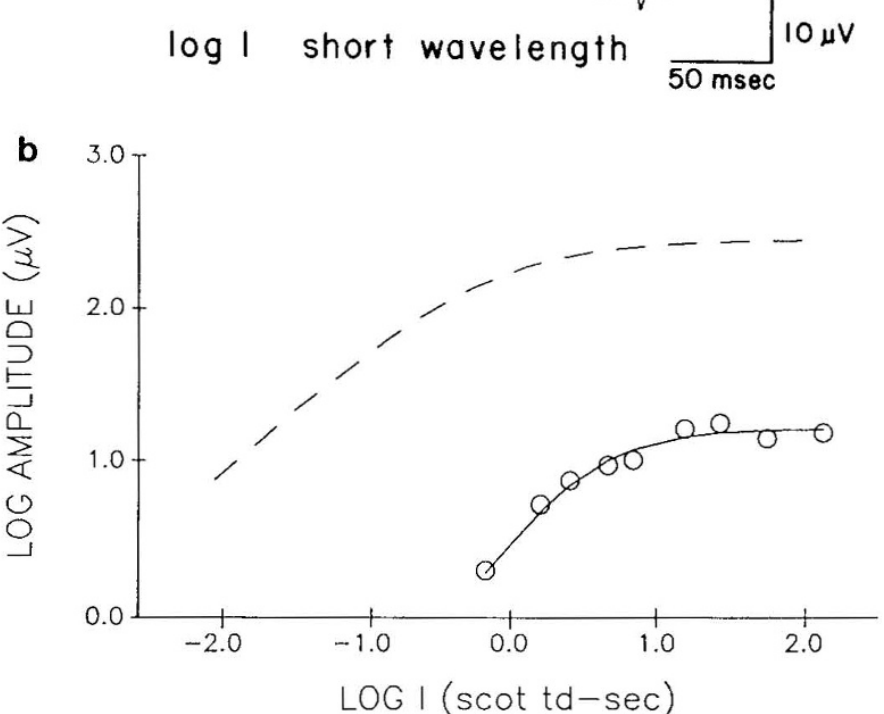

Fig. 4. $a$, Full-field ERG to short-wavelength stimuli from a representative infant at $36 \mathrm{wk}$ conceptual age. Retinal illuminance $(\log I)$ to the left of each trace is shown in log scotopic troland-s (scot td-sec). Bwave implicit time decreases with increasing retinal illuminance, consistent with rod function. Rod responses to stimuli higher than $1.0 \mathrm{log}$ scotopic troland-s were computer-isolated by subtracting responses to photopically-matched stimuli. $b$, Log rod peak-to-peak amplitude as a function of retinal illuminance $(\log I)$ for the infant shown in $a$. Solid curve is best-fit Naka-Rushton function with the exponent constrained to 1.0. Dashed curve is average Naka-Rushton function from 15 normal adult subjects (24).

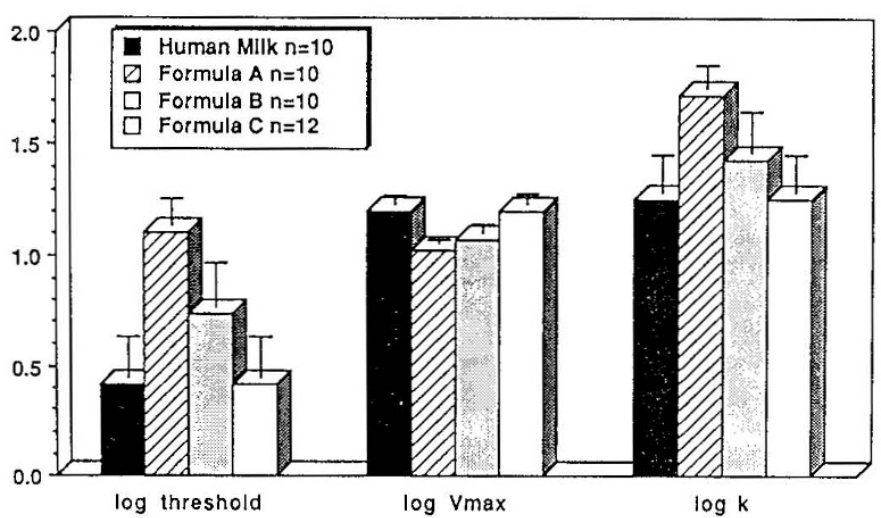

Fig. 5. Summary of rod ERG parameters for 42 infants at $36 \mathrm{wk}$ conceptual age derived from Naka-Rushton functions (mean $+\mathrm{SD}$ ). Significant diet group effects were found for threshold and $V_{\max }$, ANOVA $p<0.03$ and $<0.005$, respectively. Formula A was significantly different from human milk- and formula C-fed groups. Formulas A and B were not significantly different from each other (Newman Keuls post hoc testing). See Materials and Methods for description of Naka-Rushton functions.

$\omega-6 / \omega-3$ FA ratio further limits the desaturation of available $18: 3$ $\omega-3(8,13,15,16)$. Teleologic evidence based on the FA composition of human milk also points to a requirement for $\omega-3 \mathrm{FA}$, including DHA, in early life $(4,19-21)$.

The need to provide preformed long-chain $\omega-3$ PUFA was also a focus of this research. Present infant formulas contain trace amounts of FA longer than 18 carbon atoms chain length. Studies by several investigators have demonstrated lower DHA levels in formula-fed infants relative to human milk-fed infants $(4,31$, 32 ). The recommendation to supplement formulas with longchain $\omega-3$ FA has been suggested by us and others $(4,9,36)$. Carlson et al. (36) have used fish oil to enhance DHA content of $\mathrm{RBC}$ lipids in low-birth-weight infants and obtained FA profiles similar to infants fed human milk. We included a group fed a formula containing not only $18: 3 \omega-3$ but also the long-chain derivatives EPA and DHA from marine oils. The data reported here suggest that this group is closest to human milk-fed infants in terms of both retinal function and biochemical markers of $\omega$ 3 FA status. Recent work by Anderson et al. (9) using the $\omega-3-$ deficient newly hatched chick as a model clearly indicates that 18:3 $\omega-3$ as the sole source of $\omega-3 \mathrm{FA}$ is inadequate for the biochemical development of the brain and retina. Dietary EPA or DHA supplementation during repletion induced similar DHA content of brain and retina. This study in chicks has possible implications for the human because it supports a specific need for long-chain $\omega-3 \mathrm{FA}$ in early life (9).

The electroretinographic data show a selective effect of $\omega-3$ FA on rod function. Cones are minimally affected, although the trends are similar. The pattern of development of the human retina indicates that cones except for foveal cones are morphologically more mature than rods at the time of birth. The latter 
OMEGA-3 FATTY ACIDS AND RETINAL FUNCTION

Table 4. FA composition of total plasma lipids after consuming study diets (mean $\pm S D, g / 100 \mathrm{~g}$ lipids)*

\begin{tabular}{|c|c|c|c|c|c|c|}
\hline & \multirow{2}{*}{$\begin{array}{l}\text { Human milk } \\
\quad(n=10)\end{array}$} & \multirow{2}{*}{$\begin{array}{l}\text { Formula A } \\
(n=10)\end{array}$} & \multirow{2}{*}{$\begin{array}{l}\text { Formula B } \\
(n=10)\end{array}$} & \multirow{2}{*}{$\begin{array}{c}\text { Formula C } \\
(n=12)\end{array}$} & \multicolumn{2}{|c|}{ ANOVA } \\
\hline & & & & & $F$ & $p$ \\
\hline Saturated & $34.3 \pm 2.5$ & $36.8 \pm 5.9$ & $33.9 \pm 1.7$ & $33.9 \pm 3.0$ & 1.5 & NS \\
\hline \multicolumn{6}{|l|}{ PUFA $\omega-9$} & $<0.0001$ \\
\hline $20: 3$ & $0.16 \pm 0.09$ & $0.18 \pm 0.09$ & $0.14 \pm 0.07$ & $0.15 \pm 0.07$ & 0.54 & NS \\
\hline \multicolumn{7}{|l|}{ PUFA $\omega-6$} \\
\hline $18: 2$ & $27.4 \pm 3.9^{a}$ & $31.4 \pm 5.7^{h}$ & $33.4 \pm 2.9^{b}$ & $32.9 \pm 2.5^{b}$ & 6.1 & $<0.002$ \\
\hline $20: 4$ & $6.2 \pm 1.9$ & $5.7 \pm 2.0$ & $5.9 \pm 1.3$ & $5.7 \pm 1.3$ & 0.2 & NS \\
\hline $22: 5$ & $0.31 \pm 0.09$ & $0.41 \pm 0.20$ & $0.34 \pm 0.16$ & $0.26 \pm 0.13$ & 1.9 & NS \\
\hline$\omega-6$ LCPUFA & $9.81 \pm 2.6$ & $9.1 \pm 2.9$ & $9.3 \pm 1.8$ & $8.9 \pm 1.9$ & 0.3 & NS \\
\hline \multicolumn{7}{|l|}{ PUFA $\omega-3$} \\
\hline $18: 3$ & $0.50 \pm 0.18^{a}$ & $0.51 \pm 0.91^{a}$ & $1.65 \pm 0.43^{b}$ & $0.71 \pm 0.16^{a}$ & 10.4 & $<0.0001$ \\
\hline $20: 5$ & $0.52 \pm 0.45^{a}$ & $0.09 \pm 0.08^{h}$ & $0.42 \pm 0.13^{a}$ & $1.32 \pm 0.28^{\circ}$ & 38.1 & $<0.0001$ \\
\hline $22: 5$ & $0.36 \pm 0.19^{a}$ & $0.15 \pm 0.07^{h}$ & $0.47 \pm 0.18^{a}$ & $0.66 \pm 0.22^{\circ}$ & 15.3 & $<0.0001$ \\
\hline $22: 6$ & $1.44 \pm 0.55^{a}$ & $0.47 \pm 0.18^{h}$ & $1.14 \pm 0.22^{a}$ & $2.25 \pm 0.71^{\circ}$ & 22.7 & $<0.0001$ \\
\hline$\omega-3$ LCPUFA & $2.6 \pm 0.9^{a}$ & $1.0 \pm 0.3^{b}$ & $2.2 \pm 0.4^{a}$ & $4.5 \pm 1.3^{c}$ & 26.6 & $<0.0001$ \\
\hline PUFA $\omega-6 / \omega-3$ & $12.7 \pm 3.5^{a}$ & $31.3 \pm 12.3^{h}$ & $10.9 \pm 0.6^{a}$ & $8.1 \pm 1.4^{a}$ & 28.2 & $<0.0001$ \\
\hline LCPUFA $\omega-6 / \omega-3$ & $4.1 \pm 1.4^{a}$ & $10.2 \pm 3.9^{h}$ & $4.2 \pm 0.3^{a}$ & $2.0 \pm 0.3^{a}$ & 30.1 & $<0.0001$ \\
\hline
\end{tabular}

* Samples were taken 20-35 d after randomization as described in Materials and Methods. Groups with different superscripts are significantly different $(p<0.05)$ using Newman-Keuls multiple comparison test.

Table 5. FA composition of RBC total lipids after consuming study diets (mean $\pm S D, g / 100 \mathrm{~g}$ lipids)*

\begin{tabular}{|c|c|c|c|c|c|c|}
\hline & \multirow{2}{*}{$\begin{array}{l}\text { Human milk } \\
\quad(n=10)\end{array}$} & \multirow{2}{*}{$\begin{array}{c}\text { Formula A } \\
(n=10)\end{array}$} & \multirow{2}{*}{$\begin{array}{l}\text { Formula B } \\
(n=10)\end{array}$} & \multirow{2}{*}{$\begin{array}{l}\text { Formula C } \\
(n=12)\end{array}$} & \multicolumn{2}{|c|}{ ANOVA } \\
\hline & & & & & $F$ & $p$ \\
\hline Saturated & $41.4 \pm 7.2$ & $43.5 \pm 10.0$ & $45.2 \pm 6.7$ & $42.6 \pm 5.7$ & 0.5 & NS \\
\hline Monounsaturated & $22.1 \pm 5.0^{a}$ & $18.8 \pm 5.4^{a . h}$ & $15.3 \pm 2.5^{b}$ & $16.9 \pm 1.7^{b}$ & 5.7 & $<0.002$ \\
\hline \multicolumn{7}{|l|}{ PUFA $\omega-9$} \\
\hline $20: 3$ & $0.24 \pm 0.20$ & $0.48 \pm 0.31$ & $0.41 \pm 0.30$ & $0.31 \pm 0.30$ & 1.44 & NS \\
\hline \multicolumn{7}{|l|}{ PUFA $\omega-6$} \\
\hline $18: 2$ & $9.8 \pm 2.2^{b}$ & $12.6 \pm 3.5^{a}$ & $11.9 \pm 1.8^{a, b}$ & $11.8 \pm 1.3^{a . b}$ & 2.7 & $<0.05$ \\
\hline $20: 4$ & $11.8 \pm 4.2$ & $12.3 \pm 4.5$ & $14.3 \pm 4.6$ & $13.9 \pm 3.2$ & 0.9 & NS \\
\hline $22: 5$ & $0.94 \pm 0.79$ & $1.41 \pm 1.07$ & $1.18 \pm 0.52$ & $1.14 \pm 0.50$ & 0.7 & NS \\
\hline$\omega-6$ LCPUFA & $19.3 \pm 5.2$ & $21.0 \pm 7.1$ & $21.7 \pm 6.3$ & $21.7 \pm 4.7$ & 0.4 & NS \\
\hline \multicolumn{7}{|l|}{ PUFA $\omega-3$} \\
\hline $18: 3$ & $0.09 \pm 0.16$ & $0.14 \pm 0.16$ & $0.15 \pm 0.15$ & $0.05 \pm 0.07$ & 1.4 & NS \\
\hline $20: 5$ & $0.96 \pm 1.16^{a}$ & $0.17 \pm 0.24^{h}$ & $0.27 \pm 0.37^{a . b}$ & $0.53 \pm 0.37^{a . h}$ & 3.1 & $<0.05$ \\
\hline $22: 5$ & $1.35 \pm 0.69^{a}$ & $0.63 \pm 0.44^{h}$ & $1.05 \pm 0.45^{a . b}$ & $1.52 \pm 0.63^{a}$ & 5.0 & $<0.005$ \\
\hline $22: 6$ & $2.69 \pm 1.05^{a}$ & $1.40 \pm 1.19^{h}$ & $2.88 \pm 1.15^{a}$ & $3.71 \pm 1.70^{a}$ & 5.6 & $<0.003$ \\
\hline$\omega-3$ LCPUFA & $6.85 \pm 2.30^{a}$ & $3.20 \pm 1.80^{b}$ & $5.26 \pm 1.95^{a}$ & $6.38 \pm 2.24^{a}$ & 6.2 & $<0.002$ \\
\hline PUFA $\omega-6 / \omega-3$ & $4.7 \pm 1.6^{a}$ & $8.7 \pm 2.8^{b}$ & $6.7 \pm 1.5^{a}$ & $5.7 \pm 1.4^{a}$ & 8.3 & $<0.001$ \\
\hline LCPUFA $\omega-6 / \omega-3$ & $3.1 \pm 1.1^{a}$ & $5.3 \pm 1.9^{b}$ & $4.3 \pm 0.7^{a . b}$ & $3.6 \pm 0.6^{a}$ & 6.8 & $<0.001$ \\
\hline
\end{tabular}

* Samples were taken 20-35 d after randomization as described in Materials and Methods. Groups with different superscripts are significantly different $(p<0.05)$ using Newman-Keuls multiple comparison test.

experience significant changes postnatally. We have recently reported the differential functional maturation of cones and rods in postnatal life (23).

Photoreceptor spectral and temporal characteristics were used in our study to evaluate rod and cone function separately. We used long- and short-wavelength stimuli after $30 \mathrm{~min}$ of dark adaptation to elicit cone and rod responses, respectively. Spectral stimuli have not been previously used to isolate rod responses in preterm infants, although they are commonly used in clinical electrophysiology. Achromatic flash ERG would have resulted predominantly in a cone response and significant differences may not have been detected among diet groups. The unique FA composition of the photoreceptor outer segment suggests that the DHA content in this specialized lipid membrane plays a specific role in modulating phototransduction. Evidence from other tissues suggests that nucleotide cyclase and ribosylation of $G$ proteins may be affected by FA composition of the membrane $(6,37,38)$. Further studies are needed to clarify the mechanism by which EFA modify rod function in early life. The duration of the rod photoreceptor effect and the potential impact of dietary
EFA on the maturation of the visual cortex are part of our continuing research effort.

The effect of dietary EFA on the plasma lipid composition serves to validate our dietary intervention. Compliance with diets was not a problem because the feeding of the neonates was carefully controlled. A specific quantity of formula was fed per day. The formulas were manufactured in one batch under carefully standardized conditions; stability of the PUFA was enhanced by addition of $\alpha$-tocopherol and monitored to assure that peroxidation was minimal. The plasma FA patterns observed parallelled the composition of the feeding. Further information can be gained from examining the subclasses of plasma lipids; specific results on phospholipids, triglycerides, cholesterol esters, and FFA will be reported separately. The plasma data is concordant with the design of the study, indicating that the $\omega$-3-deficient group indeed had lower circulating levels of long-chain $\omega-3$ PUFA, including DHA.

These data also show clear evidence of $\omega-6$ sufficiency in all groups, inasmuch as 18:2 $\omega-6$ and 20:4 $\omega-6$ were similar and within normal limits; furthermore, $20: 3 \omega-9$, a biochemical 
marker of EFA deficiency $(1-5,19)$, was low in all groups, confirming adequacy of $\omega-6$ EFA supply. As expected, EPA in plasma was highest in the group fed marine oil, group $\mathrm{C}$. It appears that the metabolic conversion of EPA is under physiologic control because the EPA/DHA of the formula is higher than that found in plasma of group $C$ infants. The limitations of compositional data should be considered in interpreting the metabolic interrelations of the EFA and their derivatives. In vivo studies of EFA metabolism using labeled precursors are needed. The use of stable isotopes and the development of suitably marked tracers to identify in vivo desaturation, elongation, and oxidation are challenges for the future.

The RBC membrane composition was less affected by diet than was the plasma after $20-35 \mathrm{~d}$ of feeding the test formulas. This finding is explained by the fact that the RBC population represents a combination of preexisting $\mathrm{RBC}$ and newly formed ones. The degree of exchange of plasma and RBC membrane $\mathrm{FA}$ is not fully known. Yet, phospholipids within the membrane are constantly interchanged with plasma phospholipids and FFA. Because the composition of membranes is more tightly regulated and less diet sensitive than plasma lipids, these results could be anticipated. It is of interest that the relative content of $18: 3 \omega-3$ in RBC lipids of group B shows no clear indication of enhanced dietary supply. EPA content is higher in the human milk-fed group and group $\mathrm{C}$ but does not appear to accumulate significantly in the membrane lipids. This confirms the results of Anderson et al. (9) demonstrating active conversion of EPA to DHA in early life; alternatively, EPA content of membranes may be under physiologic regulation. The low $\omega-3$ LCPUFA, 18:3 $\omega$ 3 -derived compounds, in group A are of interest because this suggests that other membranes with high $\omega-3$ FA content and fast turnover rates, such as rod outer segments, may exhibit parallel changes. Studies in the rat indicate that diet-induced changes in RBC membrane lipids are paralleled by the changes in brain and other tissue (16). Thus, a low $\omega-3$ content and a high long-chain $\omega-6 / \omega-3$ PUFA ratio in RBC may serve as proxy indicators of poor $\omega-3$ supply to the retina. This is supported by the highly significant correlations found for the markers of $\omega-3$ FA status in plasma and RBC membranes with the indices of rod function.

Our study clearly supports the view that $\omega-3$ FA should be considered essential nutrients in early life. The rod electroretinographic responses suggest that the parent EFA, 18:3 $\omega-3$, may be insufficient to fully satisfy this requirement. Indeed, the results indicate that a supply of long-chain $\omega$-3 PUFA was necessary to sustain rod function similar to that found in the human milkfed group. The biochemical measurements provide further evidence documenting the alterations induced by a low $18: 3 \omega-3$ diet.

Acknowledgments. The authors thank the Mead-Johnson Nutritional Division for providing the infant formula products used in this study. The expert nursing collaboration of Dawn Waidelich, R.N. and Mary Nickel, R.N., the laboratory assistance of Joy Burns, Jane Anderson, and Helen Price, and the careful typing of this manuscript by Mary Blanchett are gratefully acknowledged.

\section{REFERENCES}

1. Paulsrud JR, Pensler L, Whitten CF, Stewart S, Holman RT 1972 Essential fatty acid deficiency in infants induced by fat-free intravenous feeding. Am J Clin Nutr 25:897-904

2. Caldwell MD. Johnsson HT. Othersen HB 1972 Essential fatty acid deficiency in an infant receiving prolonged parenteral alimentation. J Pediatr 81:894898

3. White HB, Turner MD. Turner MS, Miller RC 1973 Blood lipid alterations in infants receiving intravenous fat-free alimentation. J Pediatr 83:305-313

4. Uauy R. Treen M, Hoffman DR 1989 Essential fatty acid metabolism and requirements during development. Semin Perinatol 13:118-130

5. Sprecher H 1981 Biochemistry of essential fatty acids. Prog Lipid Res 20:1322
6. Stubbs CD, Smith AF 1984 The modification of mammalian polyunsaturated fatty acid composition in relation to membrane fluidity and function. Biochim Biophys Acta 779:89-137

7. Brenner RR, Peluffo RO 1966 Effect of saturated and unsaturated fatty acids on the desaturation in vitro of palmitic, stearic, oleic, linoleic and linolenic acids. J Biol Chem 241:5213-5219

8. Brenner RR, Peluffo RO 1969 Regulation of unsaturated fatty acid biosynthesis. Biochim Biophys Acta 176:471-479

9. Anderson GJ, Connor WE, Corliss JD 1990 Docosahexaenoic acid is the preferred dietary n-3 fatty acid for the development of the brain and retina. Pediatr Res 27:89-97

10. Clandinin MT, Chappel JE, Heim T, Swyer PR, Chance GW 1981 Fatty acid utilization in perinatal de novo synthesis of tissues. Early Hum Dev 5:355366

11. Clandinin MT, Chappel JE, Leong S, Heim T, Swyer PR, Chance GW 1980 Extrauterine fatty acid accretion in brain: implications for fatty acid requirements. Early Hum Dev 4:131-138

12. Holman RT, Johnson SB, Hatch TF 1982 A case of human linolenic acid deficiency involving neurological abnormalities. Am J Clin Nutr 35:617623

13. Neuringer M, Connor WE, Van Petten C, Barstad L 1984 Dietary omega-3 fatty acid deficiency and visual loss in infant rhesus monkeys. $J$ Clin Invest 73:272-276

14. Sanders TAB, Naismith DJ 1980 The effect of altering the linoleic $\alpha$-linolenic acid ratio in the maternal diet on foetal brain lipids. Proc Nutr Soc 39:80 A(abstr)

15. Neuringer M, Connor W, Lin D, Barsted L, Luck S 1986 Biochemical and functional effects of prenatal and postnatal omega-3 fatty acid deficiency on retina and brain in rhesus monkeys. Proc Natl Acad Sci USA 83:4021-4025

16. Carlson SE, Carver JD, House SG 1986 High fat diets varying in ratios of polyunsaturated to saturated fatty acid and linoleic to linolenic acid: A comparison of rat neural and rat cell membrane phospholipids. J Nutr $116: 718-726$

17. Wheeler TG, Benolken RM, Anderson RE 1975 Visual membranes: specificity of fatty acid precursors for the electrical response to illumination. Science 188:1312-1314

18. Lamptey MS, Walker BL 1978 Learning behavior and brain lipid composition in rats subjected to EFA during gestation, lactation and growth. J Nutr 108:358-367

19. Friedman Z 1980 Essential fatty acids revisited. Am J Dis Child 134:397-407

20. Heim T 1983 Energy and lipid requirements of the fetus and the preterm infant. J Pediatr Gastroenterol Nutr 2(suppl):16-41

21. Jensen RG, Hagerty MM, McMahon KE 1978 Lipids of human milk and infant formulas: a review. Am J Clin Nutr. 31:990-1016

22. Flynn JT 1985 An international classification of retinopathy of prematurity. In: Silverman W, Flynn J (eds) Retinopathy of Prematurity. Blackwell Scientific Publications, Boston, pp 1-19

23. Birch EE, Birch DG, Petrig B, Uauy R 1990 Retinal and cortical function of infants at 36 and 57 weeks post-conception. Clin Vision Sci 5:363-373

24. Birch DG, Fish GE 1987 Rod ERGs in retinitis pigmentosa and cone-rod degeneration. Invest Opthalmol Vis Sci 28:140-150

25. Naka KI, Rushton WAH 1966 S-potentials from luminosity units in the retina of fish (Cyprimidae). J Physiol (Lond) 185:536-599

26. Bligh EG, Dyer WJ 1954 A rapid method of total lipid extraction and purification. Can J Biochem Physiol 37:911-917

27. Morrison WR, Smith LM 1964 Preparation of fatty acid methyl esters and dimethyl acetals from lipids with boron fluoride-methanol. J Lipid Res 5:600-608

28. Haon GJ, Van Der Heide S, Wolthers BG 1979 Analysis of fatty acids from human lipids by gas chromatography. J Chromatogr 162:261-271

29. Horwitz W (ed) 1980 Official Methods of Analysis of the Association of Official Analytical Chemists. 13th Ed. Association of Official Analytical Chemists, Washington, DC

30. American Academy of Pediatrics Committee on Nutrition 1985 Nutritional needs of low-birth-weight infants. Pediatrics 75:976-986

31. Sanders TAB, Naismith DJ 1979 A comparison of the influence of breast feeding and bottle feeding on the faty acid composition of erythrocytes. $\mathrm{Br} \mathbf{J}$ Nutr 4:619-623

32. Carlson SE, Rhodes PG, Ferguson MG 1986 DHA status of preterm infants at birth and following feeding with human milk or formula. Am J Clin Nutr 44:798-804

33. Bjerve KS, Lovold Mostad I, Thoresen L 1987 Alpha-linolenic acid deficiency in patients on long-term gastric tube feeding: estimation of linolenic acid and long-chain unsaturated n-3 fatty acid requirement in man. Am J Clin Nutr 45:66-67

34. Bjerve KS, Fisher S, Wammer F, Egeland T 1989 Alpha-linolenic acid and long-chain $n-3$ fatty acid supplementation in three patients having $n-3$ fatty acid deficiency. Effect on lymphocyte function, plasma and red cell lipids, and prostanoid formation. Am J Clin Nutr 49:290-300

35. Holman RT, Johnson SB, Hatch T 1982 A case of human linolenic acid deficiency involving neurological abnormalities. Am J Clin Nutr 35:617623

36. Carlson SE, Rhodes PG, Rao VS, Goldgar DE 1987 Effect of fish oil supplementation on the n-3 fatty acid content of red blood cell membranes in preterm infants. Pediatr Res 21:507-510

37. Houslay MD Dipple I, Elliott KRP 1980 Guanosine 5'-triphosphate and guanosine $5^{\prime}-[\gamma$-imido $]$-triphosphate effect a collision coupling mechanism between the glucagon receptor and catalytic unit of adenylate cyclase. Biochem J 186:649-658

38. Ahmed SN, Alan BS, Alan SQ 1989 Dietary omega-3 fatty acids increase guanine nucleotide binding proteins and adenylate cyclase activity in rat salivary glands. FASEB J 3:A948 